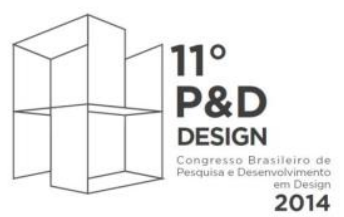

\title{
A EXPERIÊNCIA DO USUÁRIO NO PROCESSO EVOLUTIVO DO DESIGN
}

\author{
Renato do Nascimento Oliveira, Mestrando. \\ Programa de Pós Graduação em Design \\ Universidade Federal do Rio Grande do Norte \\ renatus.oliveira@gmail.com \\ Carlos Dias Limeira, Mestrando. \\ Programa de Pós-Graduação em Design \\ Universidade Federal do Rio Grande do Norte \\ carloscafedias@gmail.com \\ José Guilherme Santa-Rosa, D.Sc. \\ Programa de Pós-Graduação em Design \\ Universidade Federal do Rio Grande do Norte \\ santarosa@cchla.ufrn.br
}

\begin{abstract}
Resumo: As transformações sociais, econômicas e tecnológicas ocorridas na passagem da era industrial à pós-industrial, acabaram por redefinir o foco de intervenção do design, que passa dos produtos para as experiências dos usuários, visando atender as suas necessidades e inserindo-os como sujeitos ativos no processo de design. A partir de um levantamento bibliográfico interdisciplinar, o presente trabalho aborda como a experiência do usuário passou a ser contemplada dentro do processo evolutivo do design. Concluiu-se que a experiência do usuário, assim como o conceito de design são processos mutáveis, frutos da evolução de filosofias projetuais, tecnologias, e contextos socioeconômicos, em que seus significados são construídos tanto pelos designers que pensam a solução quanto pelos usuários que a experienciam.
\end{abstract}

Palavras-chave: Design, Experiência do Usuário, Design Emocional

Abstract: Social, economic and technological changes occurring in the transition from industrial to post-industrial period, eventually redefine the focus of intervention design, passing the products for users 


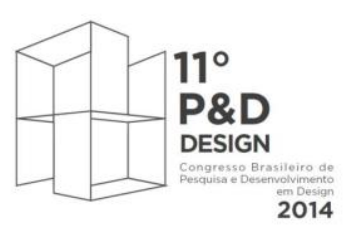

Gramado - RS

De 29 de setembro a 2 de outubro de 2014

experiences, to meet their needs and placing them as active subjects in the design process. From an interdisciplinary literature survey, this paper discusses how the user experience happened to be contemplated within the evolutionary process of design. It was concluded that the user experience, as well as the concept of design are changeable processes, the evolution of fruit projects philosophies, technologies, and socioeconomic contexts in which their meanings are constructed both by designers that think the solution for the users the experience.

Key-words: Design, User experience, Emotional Design

\section{INTRODUÇÃO}

Do período industrial até a atualidade o design passou por diferentes momentos acompanhados por sucessivas transformações no cenário socioeconômico e tecnológico que ocasionaram constantes redefinições conceituais e a expansão do seu foco de intervenção. O curso dessas transformações é marcado por reformulações nos modelos organizacionais da indústria, pelo advento das novas tecnologias, e a busca por competitividade de mercado, que impulsionaram sucessivas mudanças de estágios econômicos em que, no contexto atual, denominado por Pine e Gilmore (1998) como "economia da experiência", ocorre um forte estímulo ao desenvolvimento de pesquisas na área do design, por meio do emprego de teorias e métodos projetuais, como o Design Emocional (Emotional Design), e o Design para experiência (Experience Design), com foco em conhecer e atender às necessidades de um usuário mais interessado em viver experiências, do que propriamente na aquisição de produtos.

\section{DESIGN, SOCIEDADE E ECONOMIA}

Durante a primeira metade do século XX, segundo Cardoso (2008), houve a predominância de uma tendência essencialmente funcionalista no design, popularizando o mote "a forma segue a função" que buscava priorizar a visão utilitária dos artefatos na relação usuário-produto, em que a estética dava suporte a tal diretriz. Neste período, a área do design assumiu uma posição mais centralizadora, levando os designers a projetarem de forma indutiva e descontextualizada de cenários de uso individuais, sendo influenciados por um contexto de desenvolvimento tecnológico incipiente marcado pela ausência de pesquisas com os usuários. 


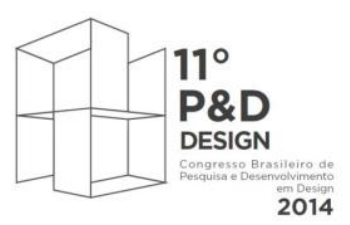

Gramado - RS

De 29 de setembro a 2 de outubro de 2014

Ainda para Cardoso (2008), é possível perceber mesmo em transição, a partir do início da década de 1930, um ganho de importância do valor simbólico dos produtos que culminou para o advento da prática do styling, estratégia mercadológica praticada pela indústria visando impulsionar a venda dos produtos a partir de sua aparência, em um contexto marcado pela restruturação econômica após a quebra da bolsa de valores americana de 1929. O styling ficou marcado como uma filosofia que se opunha ao funcionalismo, atraindo o consumidor pela estética dos produtos, que muitas vezes tentavam disfarçar limitações e ausências de ganhos funcionais para os usuários, e contribuiu para a popularização do design como recurso estético.

Nos anos que se seguiram, especialmente no período pós-guerra (de 1945 em diante), segundo Cardoso (2008) houve notáveis avanços tecnológicos que serviriam de base para a expansão industrial nesse período. Com o aumento da capacidade produtiva, esse crescimento foi impulsionado, principalmente, pela expansão contínua do consumismo, que afetou significativamente o papel do design na produção industrial, alimentando assim um sistema que ficou marcado pela estratégia do descarte dos produtos, também conhecida como obsolescência programada, que almejava fazer com que os usuários trocassem seus antigos produtos por novos em períodos controlados pelo mercado. Nesse contexto, o papel do designer seria o de projetar mudanças nas características estilísticas e funcionais que provocassem a necessidade constante de compra de novos artefatos. "A meta do sistema era estimular o consumo de reposição, aproveitando uma superabundância de materiais e de capacidade produtiva para manter o crescimento contínuo do todo" (CARDOSO, 2008, p.165-166).

A partir dos anos 1960, com o desenvolvimento tecnológico e de pesquisas de marketing realizadas com consumidores, começa a haver um esforço generalizado das empresas em desenvolver produtos mais adaptados às necessidades e desejos individuais dos usuários, que se tornam cada vez mais exigentes. Nesse cenário, segundo Freire (2009), ocorrem tentativas mais consistentes em integrar os usuários ao processo de design com o emprego de técnicas qualitativas, como a pesquisa etnográfica e grupos motivacionais. Como resultado, houve uma oferta cada vez maior de produtos diversificados que visavam atender diferentes usuários e contextos de uso específicos.

No âmbito socioeconômico, a crescente valorização simbólica dos produtos demarca o início de um período de homogeneização das características estruturais do produto como diferencial mercadológico, configurando o surgimento de um cenário no qual os serviços emergem como nova prática competitiva. Para Pine e Gilmore (1998), assim como os produtos, os serviços também acabam por ingressar em um mesmo processo homogeneizador, que culmina em um novo estágio econômico, denominado pelos supracitados autores de "economia da experiência". Nesse cenário, a oferta da 


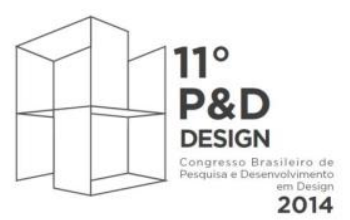

Gramado - RS

De 29 de setembro a 2 de outubro de 2014

experiência surge como um novo diferencial mercadológico, fazendo surgir investimentos no design centrado nas experiências dos usuários, e diferindo assim dos estágios anteriores que focavam primordialmente a aquisição dos produtos pelos usuários.

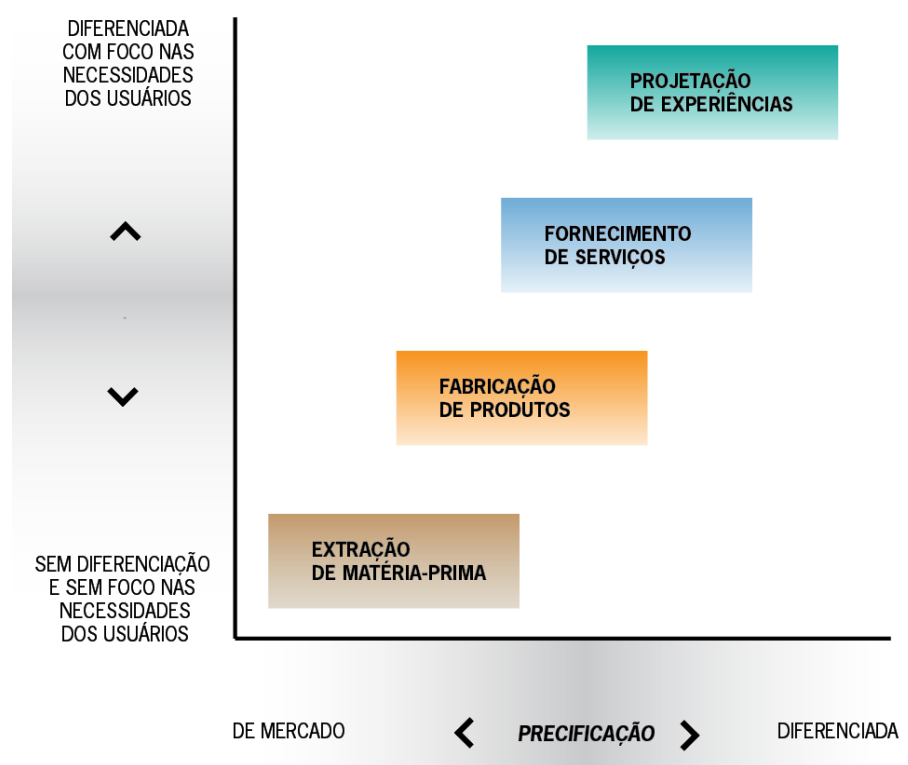

Figura 1 - Progressão do valor econômico na era pós-industrial. Fonte: Adaptado de Pine e Gilmore (1998).

A mudança de cenário econômico (Figura 1), denominada por Pine e Gilmore (1998) de "Progressão do Valor Econômico", levou as empresas a adotarem uma nova postura, partindo de um cenário no qual a centralidade estava na oferta de produtos e serviços comoditizados caracterizado por um baixo nível de competitividade de mercado (em que o único diferencial seria o preço) e sem foco nas necessidades dos usuários consumidores, para um novo cenário fundamentado na projetação de experiências como estratégia mercadológica para a geração e aumento do diferencial competitivo com foco nas necessidades dos usuários.

Esses acontecimentos de ordem social, econômica e tecnológica estão relacionados com a mudança da visão de mundo e dos padrões comportamentais dos indivíduos, caracterizando um sujeito pós-moderno orientado a um ethos mais teatral, do brincar/jogar (RIFKIN, 2001), que busca experiências estimulantes para satisfazer os seus sonhos, influenciando e sendo influenciado pelo mundo que o cerca e pelo impacto das 


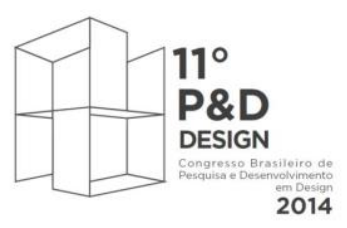

Gramado - RS

De 29 de setembro a 2 de outubro de 2014

experiências materiais e afetivas que ajudam por criar sua própria identidade. Nesse novo estágio em que as necessidades subjetivas dos usuários tornam-se essenciais, observa-se, também, uma mudança de foco no papel dos designers, que além de criadores de formas e significados, buscam transformar sonhos em realidade, atuando como verdadeiros viabilizadores de experiências.

Com o intuito de contemplar as novas práticas de mercado, assim como as novas exigências e preocupações do sujeito pós-moderno, pesquisas com usuários no design surgem com o intuito de melhor compreender a experiência subjetiva e afetiva da relação usuário-produto. Toneto e Costa (2001) apontam que a partir dos anos 1990, passa a ocorrer uma investigação científica das emoções e a sua influência no comportamento dos usuários, possibilitando o surgimento de produtos mais adaptados às necessidades e desejos dos mesmos.

\section{A EXPERIÊNCIA DO USUÁRIO}

A experiência permeia a vida humana em todos os aspectos, em que para Dewey (1980), constitui-se fruto da interação de pessoas com o contexto em que vivem. Nesse sentido, o fenômeno da experiência sempre existiu, e segundo Ferreira (2011), está intimamente ligado aos cinco sentidos humanos, que por sua vez, interagem com a cognição do sujeito em atividades cotidianas.

No âmbito do design, para Mclellan (2000), o foco nas experiências começa a figurar de forma mais contundente em projetos realizados a partir dos anos 1990, com a emergência da "economia da experiência". Nos períodos anteriores, as abordagens refletiam produtos ou serviços primordialmente voltados para as suas características estruturais (forma e função) como, por exemplo, os relógios, que durante muito tempo, para Cardoso (2012) foram tratados como objetos limitados a sua função de uso, sendo hoje convertidos em elementos de moda customizados que tentam satisfazer os desejos individuais dos consumidores, revelando assim uma preocupação sobre experiência de uso e respostas emocionais dos usuários tão determinantes quanto à preocupação com materiais e processos de fabricação.

Para Hartson e Pardha (2012) a experiência do usuário (user experience) é a totalidade do efeito ou efeitos sentidos internamente por um usuário como resultado da interação com um dado ambiente ou contexto de uso. Além dos fatores internos humanos, de acordo com Unger e Chandler (2009), a experiência do usuário é influenciada por outros elementos externos como as pessoas e objetos que um indivíduo pode interagir através dos seus sentidos, bem como as atividades realizadas nesse contexto. 


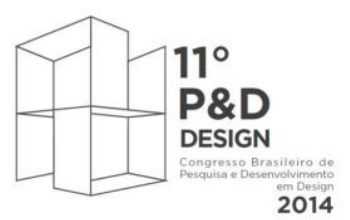

Gramado - RS

De 29 de setembro a 2 de outubro de 2014

Em nossa experiência com produtos podemos satisfazer algumas necessidades físicas e psíquicas, sendo que as interações oriundas dessa relação homem-produto, para Hekkert (2007), podem acontecer em diversos níveis:

- Interação instrumental - em que o indivíduo interage com um produto para realizar uma tarefa específica (ex.: utilizar o controle remoto da televisão para verificar a programação);

- Interação não-instrumental - em que o indivíduo manipula o produto sem fins práticos (ex.: admirar a textura ao acariciar um sofá);

- Interação não-física - em que o indivíduo pensa sobre o produto, lembrando experiências passadas ou antecipando futuras experiências (ex.: imaginar como o novo sistema de computador funciona).

Assim, para Desmet e Hekkert (2007) a experiência do usuário com produtos pode ser entendida não como uma propriedade do produto (passível de manipulação pelo designer), mas sim como o resultado da interação do usuário com o mesmo, abrangendo além da interação instrumental ligada a facilidade de uso (usabilidade), percepções, reflexões e sentimentos na relação entre usuário e artefato. Como exposto na Figura 2, o usuário estabelece uma relação com o objeto da interação antes mesmo do contato físico, por meio de expectativas e anseios, seguindo pelo momento da interação e pela reflexão pós-uso.

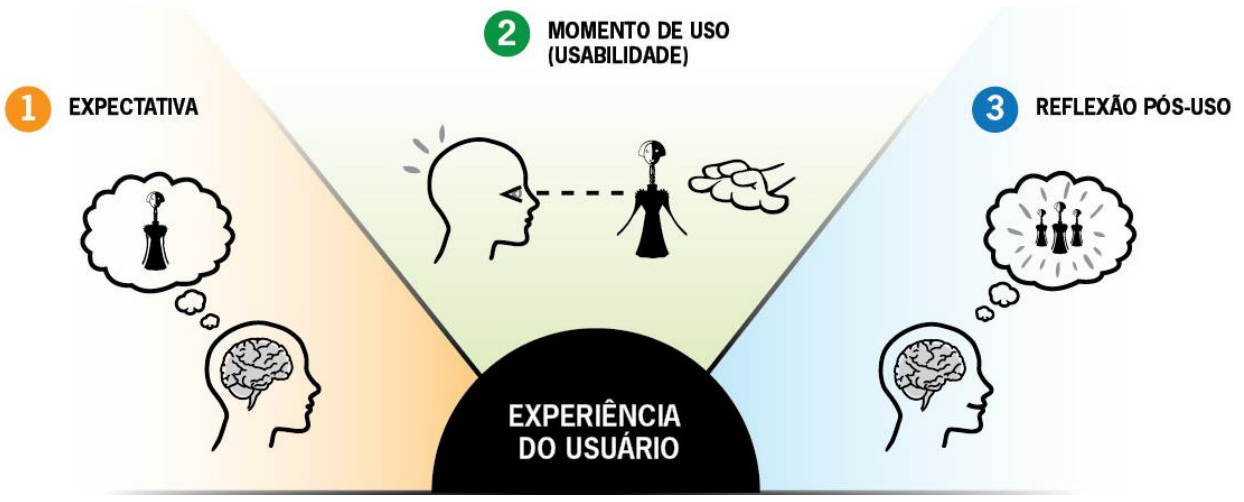

Figura 2 - Etapas da experiência do usuário. Fonte: Autores da pesquisa realizada.

Podemos observar que enquanto a experiência do usuário se estende a todos os momentos da interação e se relaciona, fundamentalmente, com aspectos subjetivos da 


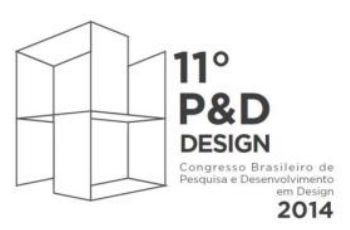

Gramado - RS

De 29 de setembro a 2 de outubro de 2014

complexidade humana, a usabilidade, em termos funcionais-humanos (SANTA ROSA e MORAES, 2008) ocorre no momento da interação, e atende primordialmente a aspectos práticos e objetivos, correspondentes à eficácia, eficiência e facilidade de uso, e uma vez que esses aspectos são atendidos, a usabilidade favorece a experiência do usuário e colabora para proporcionar agradabilidade e a satisfação durante a interação.

Portanto, no desenvolvimento de produtos interativos, como aponta Preece, Rogers e Sharp (2005) deve-se contemplar metas de usabilidade (objetivas) e metas decorrentes da experiência do usuário (subjetivas) com o intuito de projetar, significativamente, para a experiência do usuário.

\section{PROJETANDO PARA A EXPERIÊNCIA DO USUÁRIO}

Projetar produtos interativos usáveis, segundo Preece, Rogers e Sharp (2005) requer que seja levado em conta por quem serão utilizados e o seu contexto de uso. Outra preocupação importante consiste em entender o tipo de atividade que as pessoas realizam quando estão interagindo com os produtos.

Desse modo, em um projeto para a experiência do usuário, é preciso considerar um conjunto de elementos: para quem vamos projetar (é necessário conhecer especificidades correspondentes ao usuário que irá participar da experiência); o que será projetado como objeto da experiência (se é um produto, um serviço, uma interface, ou uma nova tecnologia); o objetivo da interação (como por exemplo, criar uma experiência de interação imersiva por meio de uma interface atraente e fácil de operar); onde a experiência ocorrerá (seu contexto específico de uso seja este físico, social, tecnológico, etc.); e quando a experiência ocorrerá (considerando que, de acordo com aspectos cognitivos e emocionais do usuário, a experiência pode iniciar antes mesmo da interação).

Dada complexidade das relações entre os fatores humanos e contextos que compõem uma experiência, bem como suas características intrínsecas, pesquisas desenvolvidas no campo do Design Emocional (Emotional Design) - subárea recente do design - buscam compreender a experiência subjetiva na relação humano-produto e assim projetar com foco nas emoções.

A preocupação central do design, segundo Bonsiepe (2012), está justamente na otimização da relação usuário e produto, contribuindo para o processo de desenvolvimento do produto de forma integrada, em que, a aparência do produto não deve ser interpretada de forma especial como algo agregado, mas sim conformada com a estrutura da solução. Desse modo, por meio da aparência, o designer busca imprimir personalidade ao produto, estimulando as emoções e comportamentos dos usuários. 


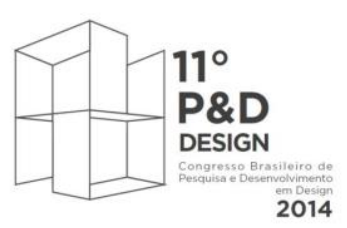

Gramado - RS

De 29 de setembro a 2 de outubro de 2014

Embora não sejam previsíveis nem controláveis por parte do designer, as emoções podem ser estudadas a fim de conhecer o seu impacto no comportamento dos usuários. Sendo assim, é importante esclarecer um aspecto essencial para uma compreensão do projeto de design de interação: não é possível projetar emoções em um produto. Portanto, não se pode "projetar a experiência do usuário", mas sim "projetar para a experiência do usuário".

Projetos com foco nas emoções humanas já vinham sendo desenvolvidos anteriormente na área do design, porém sem a devida comprovação científica dos reais impactos causados pelos produtos em sua relação com usuários, o que acabou levando os projetistas, a trabalharem de forma arbitrária ou indutiva na tentativa de criar produtos que causassem determinadas sensações nas pessoas. $O$ estudo das emoções no design, de caráter interdisciplinar, surge portanto com o propósito de fornecer suporte aos projetos de design com foco nas experiências dos usuários, contando com contribuições de áreas como a ergonomia, a psicologia e a antropologia.

Nesse sentido torna-se essencial envolver os usuários no desenvolvimento do projeto, com a possibilidade de investigar de forma mais direta e aprofundada a interação deste produto com pessoas por meio de testes e demais instrumentos de coleta de dados. Durante a experiência subjetiva com o produto, as emoções dos usuários são evocadas pelos atributos ali encontrados, em que, de acordo com Norman (2008), estímulos contribuidores para o bem-estar de um usuário tendem a despertar emoções prazerosas, enquanto que aqueles considerados ameaçadores ou prejudiciais despertam emoções ruins.

De acordo com Mccarthy e Wright (2000), o Design para a experiência (Experience Design), como objeto de estudo e área projetual, pode ser melhor compreendido quando analisados de forma integrada, em que necessidades humanas estão inter-relacionadas com fatores tecnológicos, estéticos, organizacionais e ambientais, influenciando um ao outro, atendendo a certo nível de organização e compartilhando finalidades em comum. Para os supracitados autores, a experiência está nas relações entre as partes e deve ser entendida como um todo, abrangendo os contextos socioculturais e o imediato da utilização.

\section{CONCLUSÃO}

O Design evolui em consonância com as transformações que ocorrem na sociedade, e com as consequentes mudanças de percepções, comportamentos e necessidades das pessoas. Essas transformações em escala global não tem afetado a 


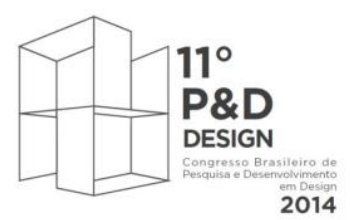

Gramado - RS

De 29 de setembro a 2 de outubro de 2014

indústria de maneira homogênea, e configura um novo cenário competitivo em expansão fundamentado na projetação para as experiências dos indivíduos.

Isso exige das organizações uma readequação de seus valores e sua identidade, e na forma como se comunicam com seus clientes, levando os designers a projetarem soluções integradas, que além de contemplar as necessidades físicas e psíquicas dos usuários, possam transformar sonhos em realidade através de experiências memoráveis.

Assim, conclui-se que o conceito de design pode ser entendido como fruto/resultado do seu tempo, consequência de filosofias e contextos, que vai muito além da aplicação de princípios funcionais e estéticos, abrangendo de forma mais ampla o favorecimento de verdadeiras experiências que integrem pessoas, objetos e ambientes.

\section{REFERÊNCIAS}

BONSIEPE, Gui. Design como prática de projeto. São Paulo: Blucher, 2012.

CARDOSO, Rafael. Uma introdução a história do design. São Paulo: Blucher, 2008. . Design para um mundo complexo. São Paulo: Cosac Naify, 2012.

DESMET, Pieter; HEKKERT, Paul. Framework of Product Experience. Internacional Journal of Design, vol. 1, n. 1, mar, 2007.

DEWEY, John. Experiência e Natureza; Lógica: a teoria da investigação; A arte como experiência; Vida e educação; Teoria da Vida moral. São Paulo: Abril Cultura, 1980.

FERREIRA, Nicholas Gabriel M. L. O papel da experiência na filosofia de Jonh Dewey. (2011). Filogênese, São Paulo, vol. 4, n.ㅇ 2, p. 147-156, 2011.

FREIRE, Karine. Reflexões sobre o conceito de design de experiências. Strategic Design Research Journal, n.22 (1), p. 37-44, jan-jun, 2009.

HARTSON, Rex; PARDHA, Pyla S. The Ux Book. Process and guidelines for ensuring a quality user experience. Waltham: Elsevier, 2012.

HEKKERT, Paul. Design Aesthetics: Principles of Pleasure in Product Design. Psychology Science, vol. 48, n.o 48, p. 157-172, 2006. 


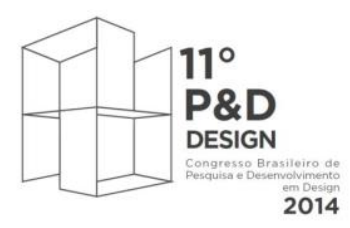

Gramado - RS

De 29 de setembro a 2 de outubro de 2014

MCLELLAN, Hilary. Experience Design. Cyberpsycology \& Behavior, vol. 3, n.ำ 1, p. 59-69, 2000.

MCCARTHY, John; WRIGHT, Peter. Technology as Experience. Cambridge, MA: MIT Press, 2004.

NORMAN, Donald Arthur. Design emocional: por que adoramos (ou detestamos) os objetos do dia-a-dia. Rio de Janeiro: Rocco, 2008.

PINE, B. Joseph; GILMORE, James H. Welcome To The Experience Economy, Harvard Business School Review. 1998.

PREECE, Jeniffer; ROGERS, Yvonne; SHARP, Helen. Design de interação: além da interação homem-computador. Porto Alegre: Bookman, 2005.

RIFKIN, Jeremy. A era do acesso. São Paulo: Makron Books, 2001.

SANTA-ROSA, José Guilherme; MORAES, Anamaria de. Avaliação e projeto no design de interfaces. Teresópolis, RJ: 2AB, 2012.

TONETTO, Leandro; COSTA, Filipe. Design Emocional: conceitos, abordagens e perspectivas de pesquisa. In Startegic Design Research Journal, 4 (3): 132-140 SetptemberDecember 2011.

UNGER, Russ; CHANDLER, Carolyn. O Guia para projetar UX. A experiência do usuário (UX) para projetistas de conteúdo digital, aplicações e web sites. Rio de Janeiro: Alta Books, 2009. 